\title{
Operating Characteristics of Multi-Injection Type Underwater Jet Pump
}

\author{
Shunichi Sakuragi ${ }^{1}$, Shendan Zhao $^{2}$ \\ ${ }^{1}$ Department of Mechanical Engineering, Shizuoka Institute of Science and Technology, Fukuroi, Japan \\ ${ }^{2}$ School of Mechanical Science and Engineering, Huazhong University of Science and Technology, Wuhan, China
}

\section{Email address:}

sakuragi.shunichi@sist.ac.jp (S. Sakuragi)

\section{To cite this article:}

Shunichi Sakuragi, Shendan Zhao. Operating Characteristics of Multi-Injection Type Underwater Jet Pump. American Journal of Mechanics and Applications. Vol. 6, No. 3, 2018, pp. 58-67. doi: 10.11648/j.ajma.20180603.11

Received: November 6, 2018; Accepted: November 26, 2018; Published: December 21, 2018

\begin{abstract}
A method of installing a jet pump at the bottom of a contaminated lake or river and stirring the contaminated area with a jet of large flow rate generated by the jet pump to promote water purification has attracted attention. By stirring the contaminated area, dissolved oxygen in the water is supplied to the stagnant area. As a result, the activity of the bacteria in the water is enhanced, and the decomposition and removal of the contaminants is promoted. In this study, the structure and operating conditions of a jet pump capable of generating a jet flow of larger flow rate with less energy consumption was pursued. In particular, the operation efficiency of the jet pump in the case of adopting the multi-nozzle injection method as the supply method of the primary jet was experimentally evaluated by precise flow rate measurement in a large tank experiment. In addition, quantitative evaluation of energy consumed by constituent equipments such as electric motors, pumps, pipelines and so on constituting the jet pump system was performed, and the total energy efficiency of the jet pump system was also evaluated. As a result, it became clear that the multi-injection method of the primary jet shows superior energy efficiency compared with the jet pump of the conventional structure.
\end{abstract}

Keywords: Underwater Jet Pump, Multi-injection Method, Amplification Factor, System Efficiency, Boundary Layer

\section{Introduction}

In the past, various studies on the performance and efficiency of jet pumps have been carried out, but in many cases the research has been conducted on jet pumps incorporated as a part of mechanical systems [1-4]. Specific examples of the research so far include various slurry transport pumps [5], suction pumps applied to deep wells [6], refrigeration cycle driven pumps using various refrigerants [7], two different fluid mixing apparatuses [8] and so on.

However, there are very few studies aimed at stirring a space filled with a large amount of water such as a lake or a river by a submerged jet pump [9-10]. Figure 1 shows an example of installing a jet pump at the bottom of a contaminated river or lake, supplying dissolved oxygen in the water to a stagnant area with a jet flow of large flow rate, decomposing and removing contaminants by activated bacteria. In this technology, it is extremely important to develop a jet pump that can generate a jet flow of high flow rate with low power consumption.

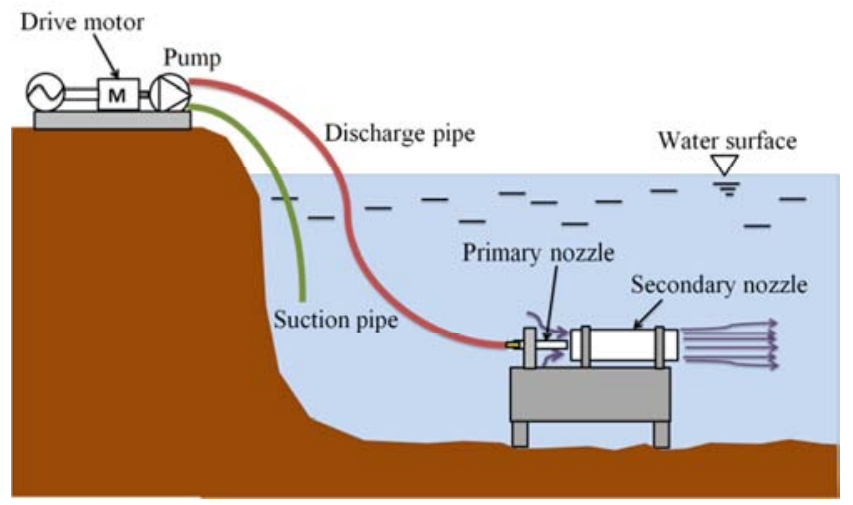

Figure 1. Schematic diagram of installation of underwater jet pump.

Zhao and Sakuragi achieved remarkable efficiency improvement by optimizing the supply method of the primary jet of the underwater jet pump [11]. This paper is the sequel pursuing the optimization of multi-injection method 
and its efficiency evaluation experimentally.

In this paper, the optimum value of the injection angle, which is an important parameter of the multi-injection system, and the optimum ratio of the flow distribution to be supplied to each primary nozzle were clarified by a tank experiment. In addition, the energy efficiency of the whole system composed of motors, pumps, pipelines and so on was also evaluated.

The main symbols used in this paper are shown below.

Nomenclature

$A$ : cross-sectional area of a secondary nozzle

$D$ : inside diameter of a secondary nozzle

$H$ : pump head

$h$ : depth of water at a probe position

$P_{F}$ : output of primary jet

$P_{I}$ : power supplied to system

$P_{P . L .}:$ pressure loss in pipe

$P_{\text {pump }}$ : shaft power of pump

$P_{S}$ : output of secondary jet

$P_{\text {water }}:$ effective power supplied to water

$P_{0}$ : total pressure of flow

$Q$ : emitted flow rate from a secondary nozzle

$q$ : total flow rate of primary jet (flow rate supplied from a drive pump, $q=q_{1}+q_{2}$ )

$q_{1}$ : emitted flow rate from a center primary nozzle

$q_{2}$ : total emitted flow rate from primary nozzles for side injection

$V$ : flow velocity

$V_{a v}$ : average flow velocity

$\Delta L$ : distance between a secondary nozzle exit and a probe

$\triangle X$ : distance between a primary nozzle and a secondary nozzle

$\eta$ : amplification factor of flow

$\eta_{M}$ : motor efficiency

$\eta_{P}:$ pump efficiency

$\theta$ : mounting angle of side nozzle

\author{
$\rho$ : fluid density \\ $\zeta_{\text {jet }}$ jet pump efficiency \\ $\zeta_{\text {sys: }}:$ system efficiency
}

\section{Experimental Apparatus and Data Analysis Method}

\subsection{Experimental Setup}

Figure 2 shows a schematic diagram of the large tank (1800 $\mathrm{mm} \times 900 \mathrm{~mm} \times 900 \mathrm{~mm}$ ) used in this study. The primary nozzle made of stainless steel has a length of $100 \mathrm{~mm}$, an outer diameter of $10 \mathrm{~mm}$ and an inner diameter of $6 \mathrm{~mm}$. The inner diameter of the secondary nozzle made of PVC is $78 \mathrm{~mm}$ and the length is $225 \mathrm{~mm}$. Furthermore, the relative position $\Delta X$ between the primary nozzle and the secondary nozzle can be adjusted (if the value of $\Delta X$ is negative, the primary nozzle is outside the secondary nozzle). Water in the tank is supplied to the primary nozzle by a centrifugal spiral pump (maximum pressure head: $23 \mathrm{~m}$, rated output: $0.4 \mathrm{~kW}$ ). The rotational speed of the three-phase AC motor that drives the pump can be controlled with the inverter (output frequency 0 to $60 \mathrm{~Hz}$ ), and the discharge flow rate can be adjusted arbitrarily.

The velocity distribution of the jet flow released from the secondary nozzle was measured using a total pressure probe. This is fixed to the 3 axis drive stage, and the position of this probe can be set accurately.

Figures 3(a) to (d) show the structure of the jet pump model used in this experiment. Figure 3(a) shows a conventional type in which the primary nozzle consists of one central nozzle. Figures 3(b), 3(c) and 3(d) show the multi-injection type in which the primary nozzle is composed of one central nozzle and four side injection nozzles installed on the side wall of the secondary nozzle.
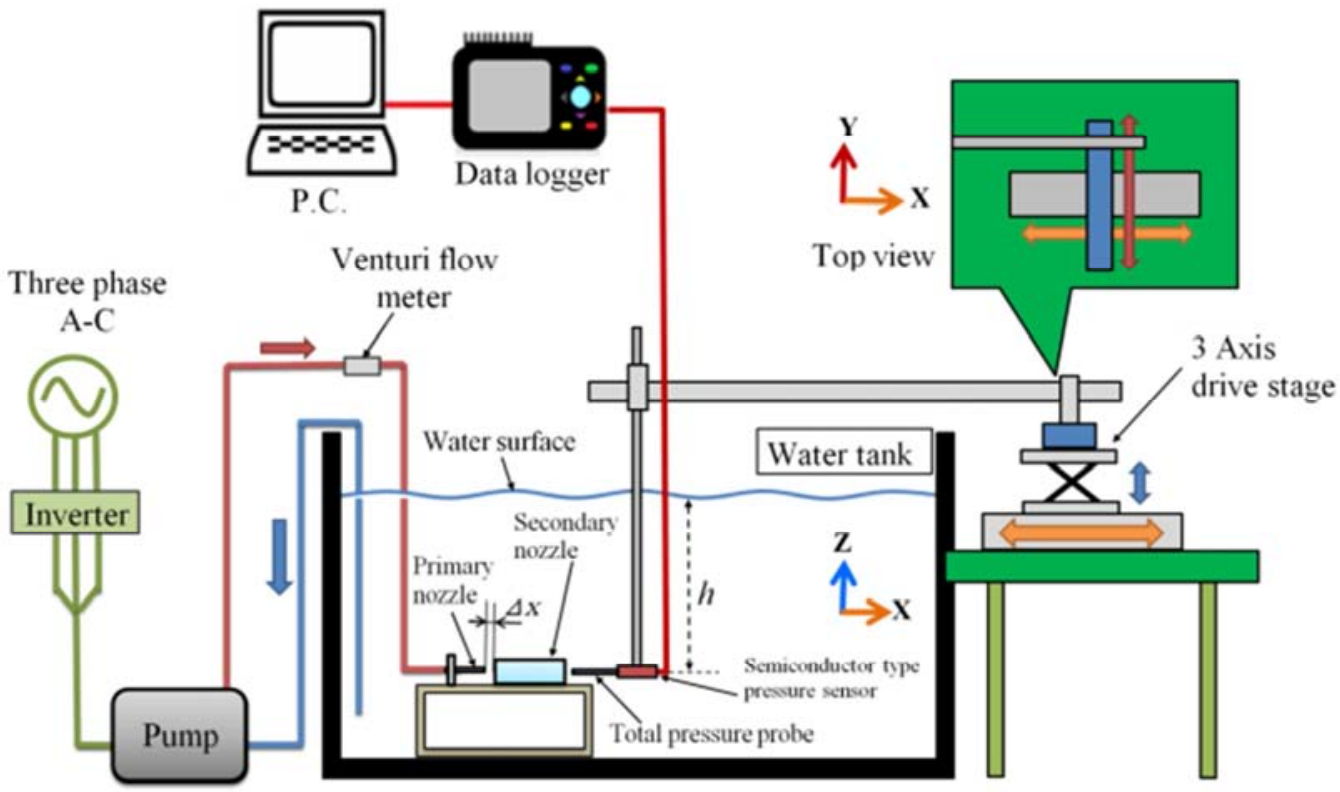

Figure 2. Schematic diagram of the tank experiment system. 


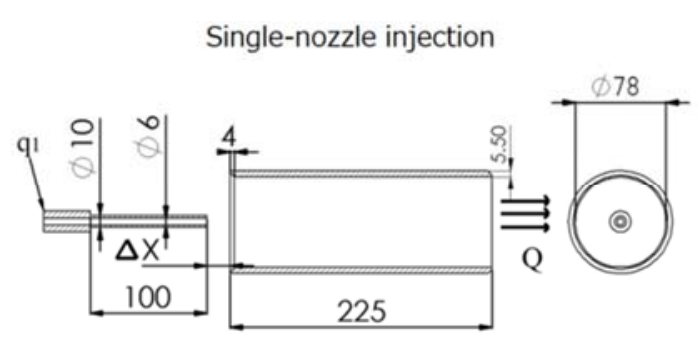

(a)

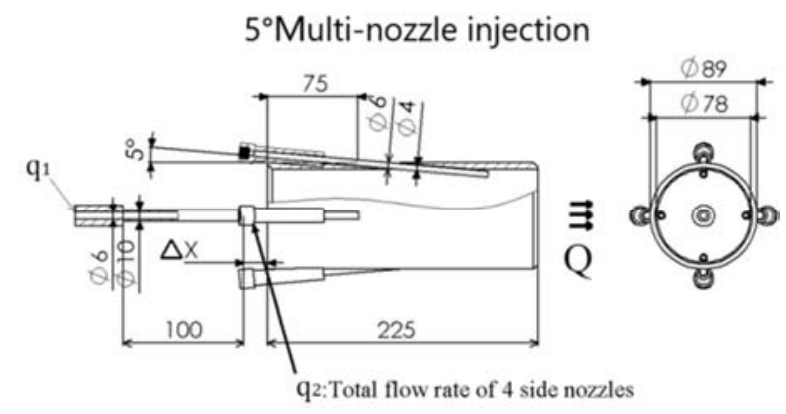

(b)

$15^{\circ}$ Multi-nozzle injection

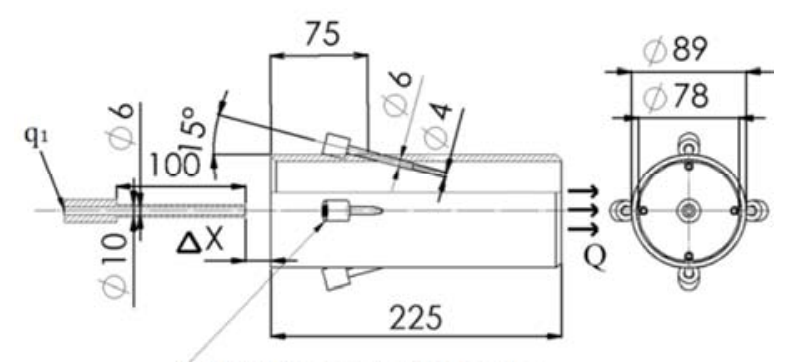

$\mathrm{q}_{2}$ : Total flow rate of 4 side nozzles

(c)

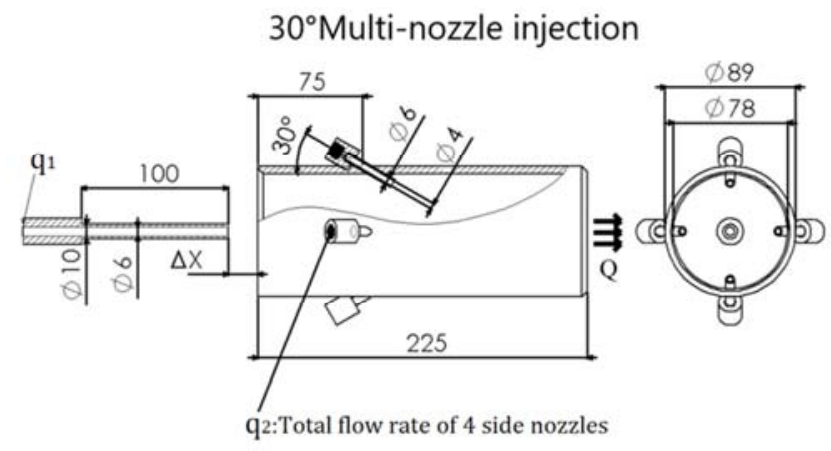

(d)

Figure 3. The jet pump models used in this study.

In these figures, the mounting angle $\theta$ of the side injection nozzles is set to $5^{\circ}, 15^{\circ}$ and $30^{\circ}$, respectively. In this case, for installation, the hole position to be drilled in the side wall of the secondary nozzle was unified at $75 \mathrm{~mm}$ from the entrance face of the secondary nozzle at all installation angles. In addition, the inner diameter of the side nozzles is all $4 \mathrm{~mm}$.

Figure 4 shows the pipeline arrangement for multi-nozzle injection. The flow rate $q$ supplied from the pump is distributed to $q_{1}$ sent to the central primary nozzle and $q_{2}$ sent to the four side injection nozzles.

Figure 5 shows the photographs of the tank experimental equipment used in this study.

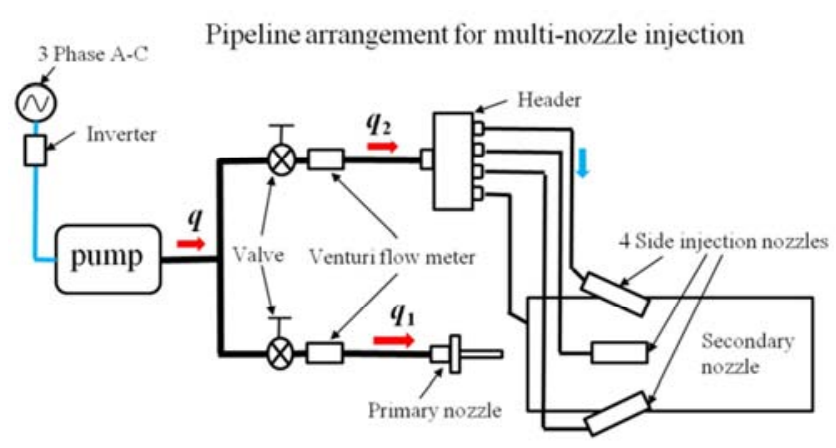

Figure 4. Pipeline arrangement for multi-nozzle injection.

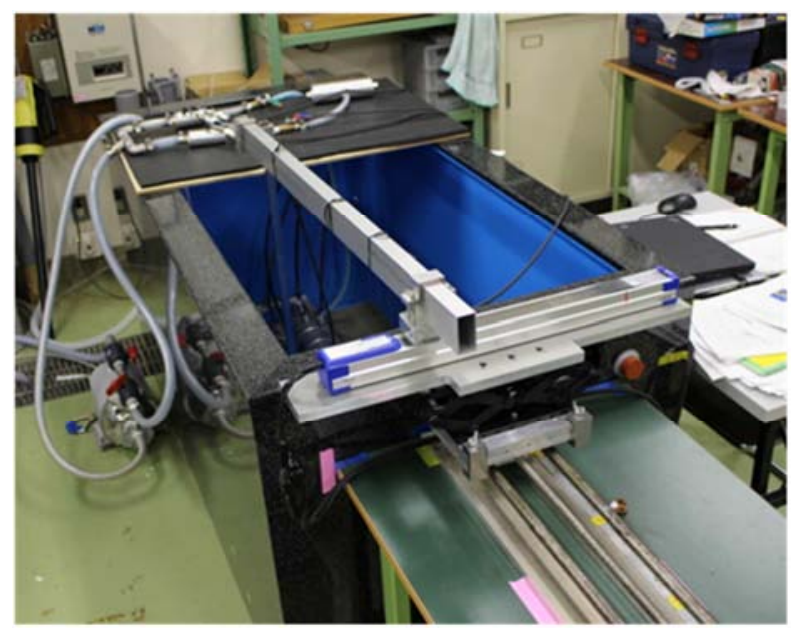

(a) Whole view of the experimental device.

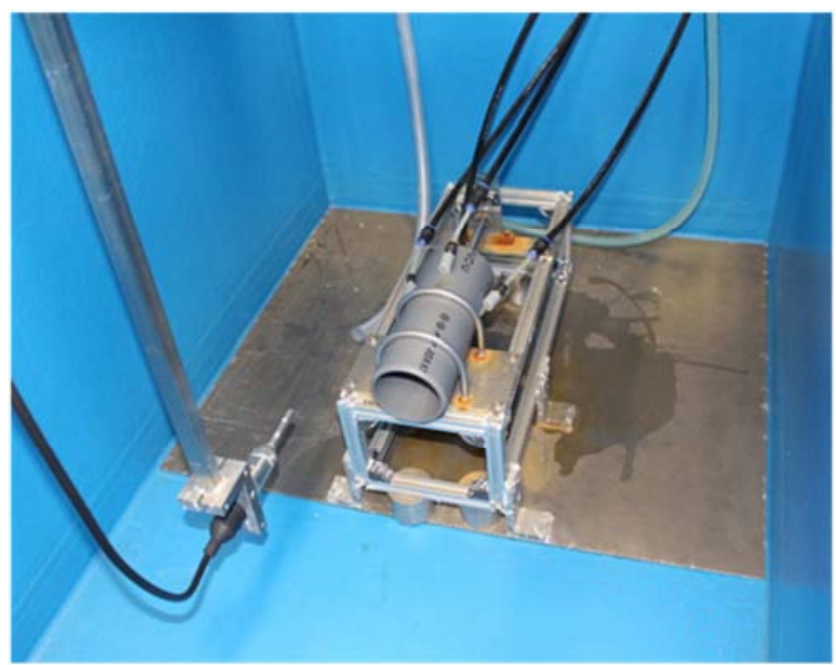

(b) Installed jet pump.

Figure 5. Photographs of the tank experimental device.

\subsection{Data Analysis Method}

The flow velocity was measured by moving the total 
pressure probe to a measurement point obtained by dividing the nozzle diameter at equal intervals on the surface $2 \mathrm{~mm}$ downstream from the outlet of the secondary nozzle. The measurement points of the flow velocity are shown in Figure 6. The total number of the velocity measurement points used for flow rate calculation is 37 .

If Bernoulli's theorem is applied with the total pressure value measured at each point as $\mathrm{P}_{0}$, the water depth at the probe position as $\mathrm{h}$, the water density as $\rho$, and the gravitational acceleration as $\mathrm{g}$, the flow velocity $\mathrm{V}$ is expressed by the following equation [12].

$$
V=\sqrt{2\left(P_{0}-\rho g h\right) / \rho}
$$

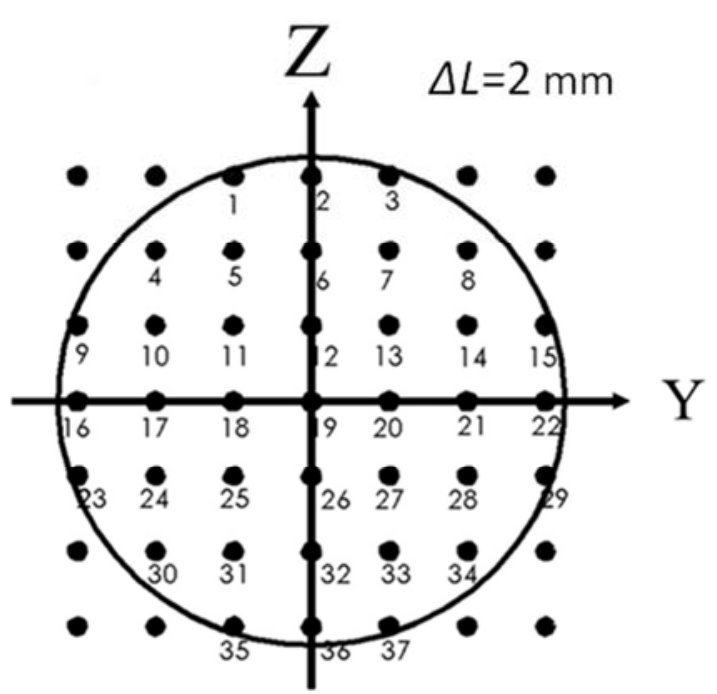

Figure 6. Measurement points of flow velocity for flow rate calculation.

Under the condition that the flow rate supplied with the pump is fixed. $q=18(\mathrm{~L} / \mathrm{min})$

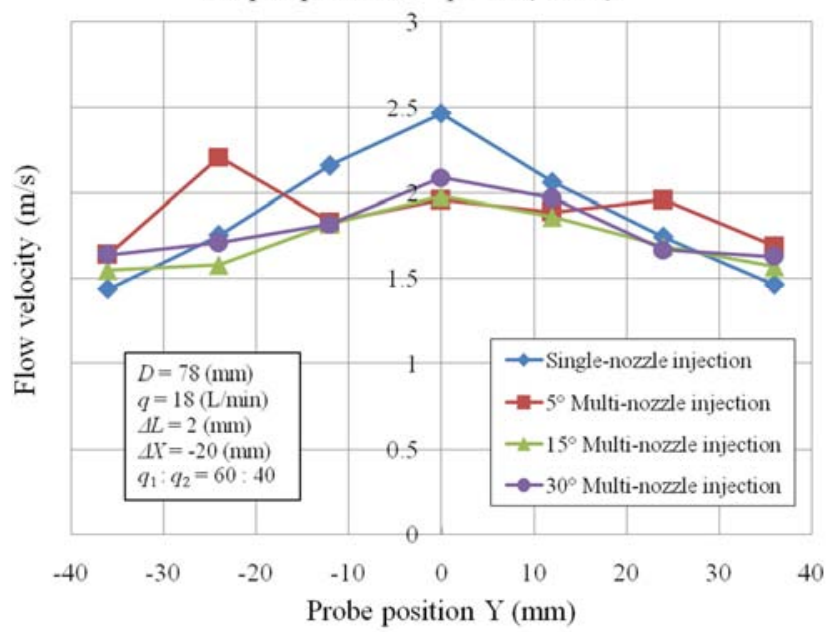

Figure 7. The velocity distributions of the jet emitted from the secondary nozzle of each model.

The flow rate $\mathrm{Q}$ discharged from the secondary nozzle is expressed by the product of the average flow velocity $\mathrm{V}_{\mathrm{av}}$ on the nozzle exit surface and the nozzle cross-sectional area A. That is,

$$
Q=A \cdot V_{a v}=A \cdot\left\{\left(V_{1}+V_{2}+\cdots+V_{37}\right) / 37\right\}
$$

Further, if the jet flow rate of a primary nozzle is set to $q$, the flow amplification factor $\eta$ is defined as follows.

$$
\eta=Q / q
$$

\section{Results and Discussion}

\subsection{Performance Evaluation of Each Model}

\subsubsection{Velocity Distribution of Secondary Jet}

The final output of the underwater jet pump depends on the velocity distribution of the jet at the exit face of the secondary nozzle.

Figure 7 shows the velocity distribution measurement result on the center axis of the secondary nozzle outlet face $(Z=0)$ of each model. This data is the result of measurement under the condition that the flow rate of the primary jet is constant at 18 $\mathrm{L} / \mathrm{min}$ in all model experiments. From the figure, in the case of the injection angle of $5^{\circ}$, the maximum flow velocity point is formed not at the center but at a position close to the exit of the side nozzle.

\subsubsection{Amplified Flow Rate and Amplification Factor}

Figure 8 is a graph showing the effect of the difference in installation angle of the side nozzles on the amplified flow rate In all the data shown in this figure, the flow rate of the primary jet is set to $18 \mathrm{~L} / \mathrm{min}$ in all cases. As shown in the figure, when the primary jet is supplied from both the center nozzle and the side nozzle $\left(q_{1}: q_{2}=60: 40\right)$, and the case where the primary jet is supplied using only the side nozzles $\left(q_{1}: q_{2}=0: 100\right)$, in either case, the injection angle of $5^{\circ}$ achieved the maximum amplified flow rate.

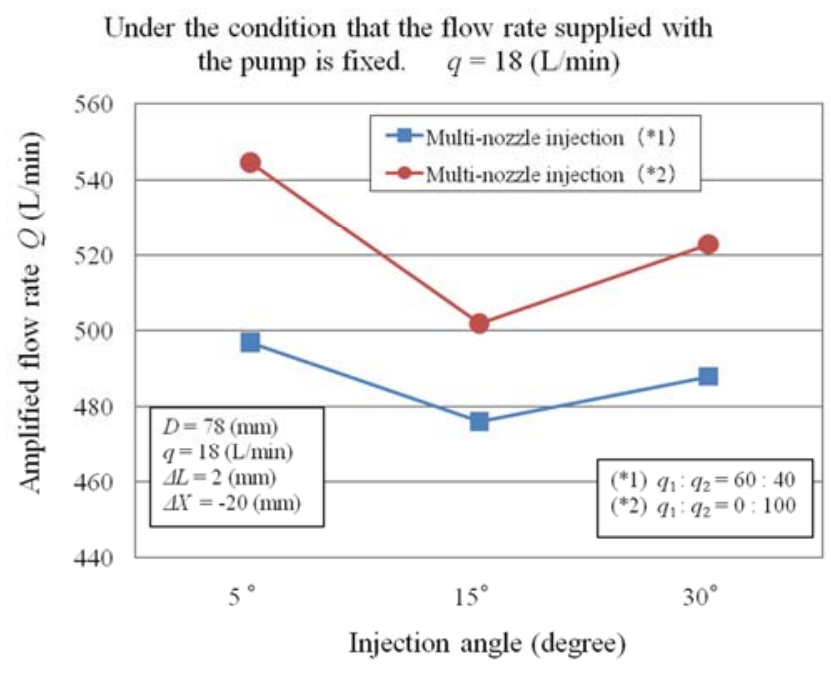

Figure 8. Influence of side nozzle installation angle on amplified flow rate.

Figure 9 shows the relationship between the flow rate of the primary jet and the amplified flow rate of each experimental model. From the figure, in all cases, the amplified flow rate tends to increase with increasing flow rate of the primary jet. Also in this case, when the injection angle is $5^{\circ}$, the largest 
amplified flow rate is generated. In the injection method using only the side nozzles, although the amplified flow rate further increases, the maximum flow rate of the primary jet tends to decrease because the pressure loss in the pipeline increases. By reducing the pressure loss, further increase of the amplified flow rate is expected.

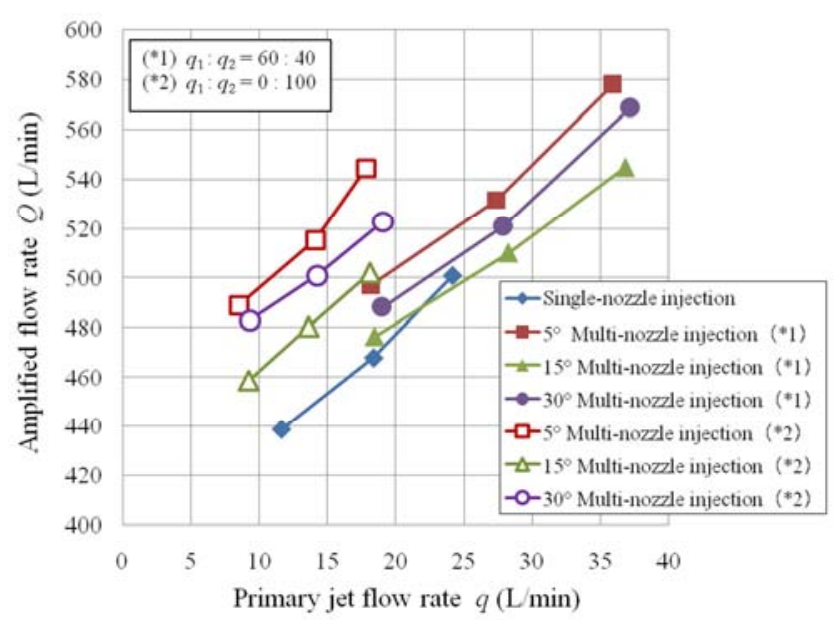

Figure 9. Correlation between the primary jet flow rate and the amplified flow rate.

Figure 10 shows the relationship between the flow rate of the primary jet and the amplification factor. The amplification factor shows a downward tendency as the primary jet flow rate increases. This is considered to be caused by an increase in energy loss related to pressure loss occurring in the secondary nozzle due to an increase in the amplified flow rate. Also from this figure, it can be seen that in the system using only the side nozzles, higher amplification factors can be obtained in the low flow rate range of the primary jet.

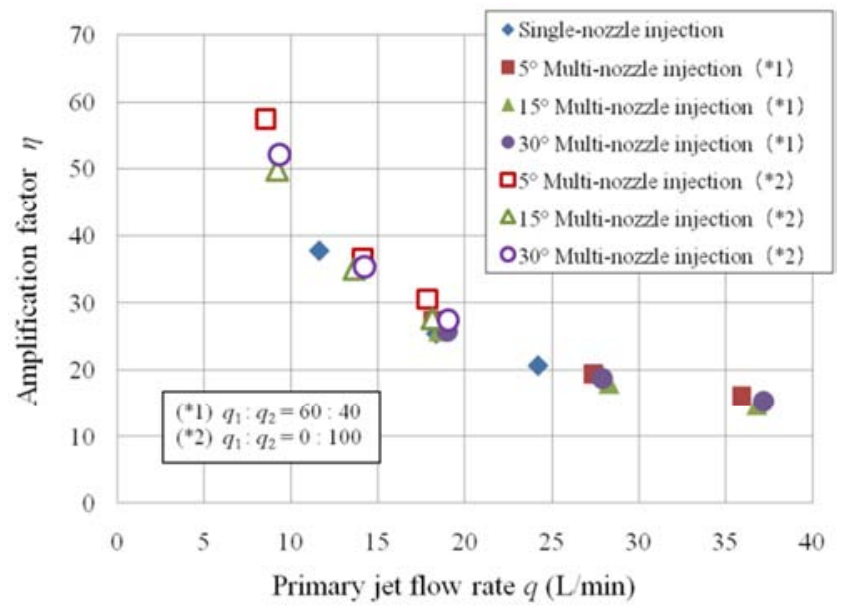

Figure 10. Correlation between the primary jet flow rate and the amplification factor.

\subsection{Energy Flow of Jet Pump System}

\subsubsection{Evaluation of Output and Loss amount of Each Component}

Figure 11 shows a flow of energy consumption of the jet pump system. The electric power $P_{I}$ input to the system is consumed as loss energy by the motor and the pump, and then supplied to the water as the effective power $P_{\text {water }}$. A part of the effective power $P_{\text {water }}$ given to the water is consumed by the pressure loss occurring in the pipeline and then released as the output $P_{F}$ of the primary jet. From this figure, it is considered reasonable to define and evaluate the following two indices for evaluating the energy efficiency of the jet pump.
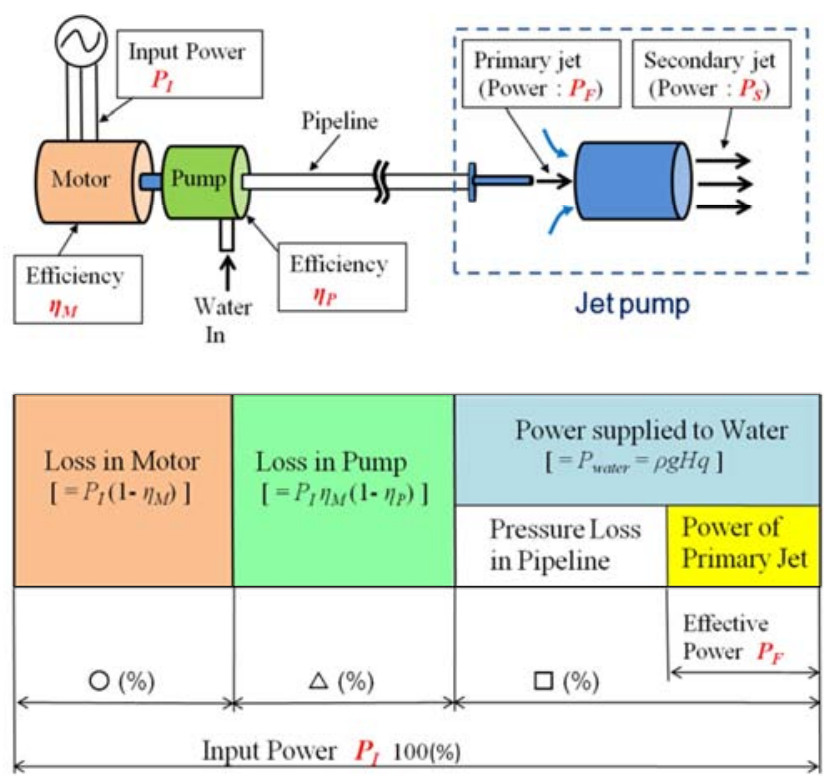

Figure 11. Energy consumption diagram of jet pump system.

$$
\begin{array}{r}
\text { System efficiency } \quad \zeta_{\text {sys }}=\frac{P_{S}}{P_{I}} \\
\text { Jet pump efficiency } \zeta_{j e t}=\frac{P_{S}}{P_{F}}
\end{array}
$$

The system efficiency $\zeta_{\text {sys }}$ is the ratio of the output $P_{S}$ of the secondary jet, which is the final utilization energy per unit time, to the supply energy $P_{I}$ from the electric power source per unit time. $P_{I}$ is given by the following equation from the measured values of line voltage $V_{l}$ and line current $I_{l}$ measured on the output side of the inverter.

$$
P_{I}=\sqrt{3} I_{l} V_{l} \cos \phi
$$

Here, $\cos \phi$ is the power factor of the motor. In this paper the value is set to 0.75 (constant value). On the other hand, the jet pump efficiency $\zeta_{\text {jet }}$ is expressed by the ratio between the output $P_{S}$ of the secondary jet and the output $P_{F}$ of the primary jet and is an index representing the energy efficiency of the jet pump itself.

\subsubsection{Output of Primary Jet and Secondary Jet}

In order to know the system efficiency $\zeta_{\text {sys }}$ and the jet pump efficiency $\zeta_{j e t}$ mentioned in the previous section, it is necessary to calculate the output of the primary jet and the secondary jet (the kinetic energy of jet flow released in unit time).

When the kinetic energy of the fluid of velocity $V$ passing 
through an arbitrary cross section ( $\operatorname{area} A$ ) in the fluid per unit time is defined as $P_{W}$, it can be expressed as follows with reference to Figure 12 [13].

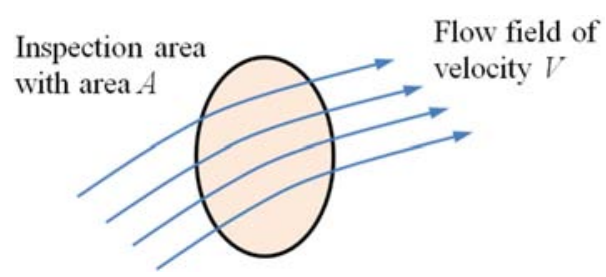

Figure 12. Fluid energy passing through an arbitrary area.

$$
P_{W}=\frac{1}{2} \dot{m} V^{2}=\frac{1}{2}(\rho A V) V^{2}=\frac{1}{2} \rho A V^{3}
$$

Where, $\dot{m}$ is the mass flow rate $(\mathrm{kg} / \mathrm{s})$ of the fluid.

On the other hand, assume that an arbitrary cross section (area $A$ ) in the fluid is composed of $n$ minute area elements $d A_{1}$, $d A_{2}, d A_{3}, \ldots, d A_{\mathrm{n}-1}, d A_{\mathrm{n}}$ as shown in Figure 13 . Then, when the flow velocity of the fluid passing through each area element is different, the kinetic energy of the fluid passing through the arbitrary section in unit time is expressed as follows [14].

\begin{tabular}{|l|l|l|l|l|}
\hline$d A_{1}$ & $d A_{2}$ & $d A_{3}$ & $\cdot$ & $\cdot$ \\
\hline$\cdot$ & $\cdot$ & $\cdot$ & & \\
\hline & & & & \\
\hline & & & & \\
\hline & $\cdot$ & $\cdot$ & $d A_{\mathrm{n}-1}$ & $d A_{\mathrm{n}}$ \\
\hline
\end{tabular}

Figure 13. An arbitrary section in a fluid composed of $n$ small area elements.

Assuming that the fluid is an incompressible fluid,

$$
\begin{aligned}
P_{W} & =\sum_{i=1}^{n} \frac{1}{2} \rho \cdot d A_{i} \cdot V_{i}{ }^{3} \\
& =\int_{A} \frac{1}{2} \rho V^{3} d A \\
& =\frac{1}{2} \rho \int_{A} V^{3} d A \\
& =\frac{1}{2} \rho\left(V_{1}^{3} d A_{1}+V_{2}^{3} d A_{2}+V_{3}^{3} d A_{3}+\cdots+V_{n}^{3} d A_{n}\right)
\end{aligned}
$$

Here, consider applying equation (8) to the flow velocity measurement points at the secondary nozzle outlet shown in Figure 6 . The kinetic energy possessed by the secondary jet passing through the secondary nozzle exit face in unit time is calculated using equation (8) as follows.

On the outlet surface of the secondary nozzle, $n$ minute area elements $d A_{1}, d A_{2}, d A_{3}, \cdot \cdot \cdot d A_{\mathrm{n}-1}, d A_{\mathrm{n}}$ can be written as $d A_{1}, d A_{2}, d A_{3}, \cdot \cdot \cdot d A_{37}$. Then, since it can be assumed that each of the minute area elements $d A_{i}$ has the same area $d A$, using the fact that $d A=d A_{1}=d A_{2}=d A_{3}=\cdot \cdot \cdot=d A_{37}$, the equation (8) can be expressed as follows.

$$
\begin{aligned}
P_{W} & =\frac{1}{2} \rho\left(V_{1}^{3} d A_{1}+V_{2}^{3} d A_{2}+V_{3}^{3} d A_{3}+\cdots+V_{n}^{3} d A_{n}\right) \\
& =\frac{1}{2} \rho d A\left(V_{1}^{3}+V_{2}{ }^{3}+V_{3}^{3}+\cdots+V_{37}{ }^{3}\right) \\
& =\frac{1}{2} \rho\left(\frac{A}{37}\right)\left(V_{1}{ }^{3}+V_{2}{ }^{3}+V_{3}^{3}+\cdots+V_{37}{ }^{3}\right)
\end{aligned}
$$

Here, $A$ represents the secondary nozzle outlet area and satisfies the relationship $A=37 d A$.

Based on the discussion so far, the output of the primary jet was calculated using equation (7) assuming that the primary nozzle has a small aperture and is regarded as one-dimensional flow. In addition, the output of the secondary jet was calculated from the flow velocity value measured at each measurement point using equation (9).

Table 1 shows these calculated values and jet pump efficiency and system efficiency. From the table, it can be seen that the multi-nozzle type exhibits an extremely high value with the jet pump efficiency as compared with the conventional type.

(From this table, you can see the value that seems a little strange. Those whose jet pump efficiency value exceeds $100 \%$ have appeared. As for this result, it is very difficult to judge whether the logic process in our data processing calculation is

\begin{tabular}{|c|c|c|c|c|c|c|c|}
\hline $\begin{array}{l}\text { Classification of } \\
\text { jet pump model }\end{array}$ & $\begin{array}{l}\text { Installation angle } \\
\text { of side nozzle } \\
\theta \text { (deg) } \\
\end{array}$ & $\begin{array}{l}\text { Inverter output } \\
\text { frequency (Hz) }\end{array}$ & $\begin{array}{l}\text { Total supply flow rate } \\
\text { of primary nozzle } \\
q(\mathrm{~L} / \mathrm{min})\end{array}$ & $\begin{array}{l}\text { Output of } \\
\text { primary jet } \\
P_{F}(W) \\
\end{array}$ & $\begin{array}{l}\text { Output of } \\
\text { secondary jet } \\
P_{S}(\mathrm{~W}) \\
\end{array}$ & $\begin{array}{l}\text { Jet pump } \\
\text { efficiency } \\
\zeta_{\text {jet }}(\%) \\
\end{array}$ & $\begin{array}{l}\text { System } \\
\text { efficiency } \\
\zeta_{\text {sys }}(\%) \\
\end{array}$ \\
\hline \multirow{2}{*}{$\begin{array}{l}\text { Single-nozzle } \\
\text { injection }\end{array}$} & & 45 & 18.36 & 17.90 & 11.56 & 64.6 & 4.6 \\
\hline & & 60 & 24.20 & 41.00 & 15.60 & 38.0 & 4.4 \\
\hline \multirow{4}{*}{$\begin{array}{l}\text { Multi-nozzle } \\
\text { injection } \\
\left(q_{1}: q_{2}=60: 40\right)\end{array}$} & \multirow{2}{*}{5} & 30 & 18.20 & 4.20 & 12.96 & 308.6 & 6.0 \\
\hline & & 60 & 35.90 & 29.10 & 26.40 & 90.7 & 6.2 \\
\hline & 15 & 30 & 18.47 & 4.06 & 11.22 & 276.4 & 5.5 \\
\hline & 30 & 30 & 18.70 & 4.34 & 12.42 & 286.2 & 6.0 \\
\hline
\end{tabular}
incorrect or gives the correct result. In the future, it is desired that the readers' verification of this result will be done over various aspects.)

\subsubsection{Evaluation of Loss Amount in Mechanical Power System (Motor and Pump)}

By evaluating the loss power generated by each

Table 1. Calculated output power of primary jet and secondary jet, and calculated jet pump efficiency and system efficiency. 


\begin{tabular}{|c|c|c|c|c|c|c|c|}
\hline $\begin{array}{l}\text { Classification of } \\
\text { jet pump model }\end{array}$ & $\begin{array}{l}\text { Installation angle } \\
\text { of side nozzle } \\
\theta \text { (deg) }\end{array}$ & $\begin{array}{l}\text { Inverter output } \\
\text { frequency }(\mathrm{Hz})\end{array}$ & $\begin{array}{l}\text { Total supply flow rate } \\
\text { of primary nozzle } \\
q(\mathrm{~L} / \mathrm{min})\end{array}$ & $\begin{array}{l}\text { Output of } \\
\text { primary jet } \\
P_{F}(W) \\
\end{array}$ & $\begin{array}{l}\text { Output of } \\
\text { secondary jet } \\
P_{S}(\mathrm{~W}) \\
\end{array}$ & $\begin{array}{l}\text { Jet pump } \\
\text { efficiency } \\
\zeta_{\text {jet }}(\%) \\
\end{array}$ & $\begin{array}{l}\text { System } \\
\text { efficiency } \\
\zeta_{\text {sys }}(\%) \\
\end{array}$ \\
\hline & & 60 & 37.20 & 30.30 & 20.50 & 67.7 & 4.9 \\
\hline Multi-nozzle & 5 & 60 & 17.80 & 5.20 & 28.30 & 544.2 & 7.9 \\
\hline injection & 15 & 60 & 18.10 & 5.40 & 14.30 & 264.8 & 3.9 \\
\hline$\left(q_{1}: q_{2}=0: 100\right)$ & 30 & 60 & 19.00 & 6.30 & 15.60 & 247.6 & 4.3 \\
\hline
\end{tabular}

component of the jet pump system, it is possible to analyze the flow of energy in the system in detail.

The water supply pump to the primary nozzle used in this experiment has a structure that drives a spiral pump with a three-phase $200 \mathrm{~V} \mathrm{AC}$ induction motor with a rated output of $0.4 \mathrm{~kW}$. Generally, about 10 to $40 \%$ of the input power is lost due to factors such as iron loss, copper loss, friction loss, etc., in the energy loss generated inside the motor. According to the Japanese Industrial Standards JIS C 4210 [15], the full load characteristic of the "general purpose $200 \mathrm{~V}$ three-phase induction motor $0.4 \mathrm{~kW}$ class" is marked with efficiency:

$62 \%$ or more, power factor: $72 \%$ or more. In this paper, we refer to this numerical value and adopt the value of motor efficiency $\eta_{M}=0.7$.

On the other hand, the pump efficiency $\eta_{P}$ can be obtained by the following procedure. First of all, the actual power $P_{\text {water }}$ that the pump gives to water can be calculated using the head curve provided by the manufacturer and the measured value $q$ of the discharge flow rate. That is,

$$
P_{\text {water }}=\rho g H \cdot q
$$

Here, $H$ is the pump head and $g$ is the gravitational acceleration. In addition, the actual power $P_{\text {pump }}$ (pump shaft power) supplied to the pump is expressed by the following equation from the electric power $P_{I}$ supplied to the motor and the motor efficiency $\eta_{M}$.

$$
P_{\text {pump }}=P_{I} \cdot \eta_{M}=0.7 P_{I}
$$

Therefore, the pump efficiency $\eta_{P}$ is expressed by the following equation.

$$
\eta_{P}=P_{\text {water }} / P_{\text {pump }}=\rho g H \cdot q /\left(0.7 P_{I}\right)
$$

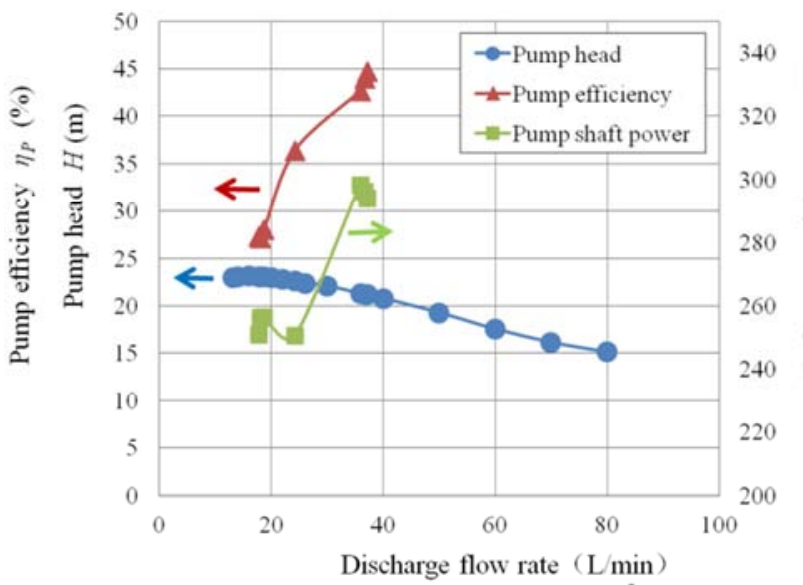

Figure 14. Pump head, pump shaft power and pump efficiency.
Figure 14 shows the relationship between the discharge flow rate by the pump and the pump efficiency, the pump head and the pump shaft power.

Figure 15 shows the efficiency curve of the spiral pump extracted from JIS B 8313 [16] as a reference diagram. From Figure 15 , it can be understood that the pump efficiency is very low in the small spiral pump having a small discharge flow rate.

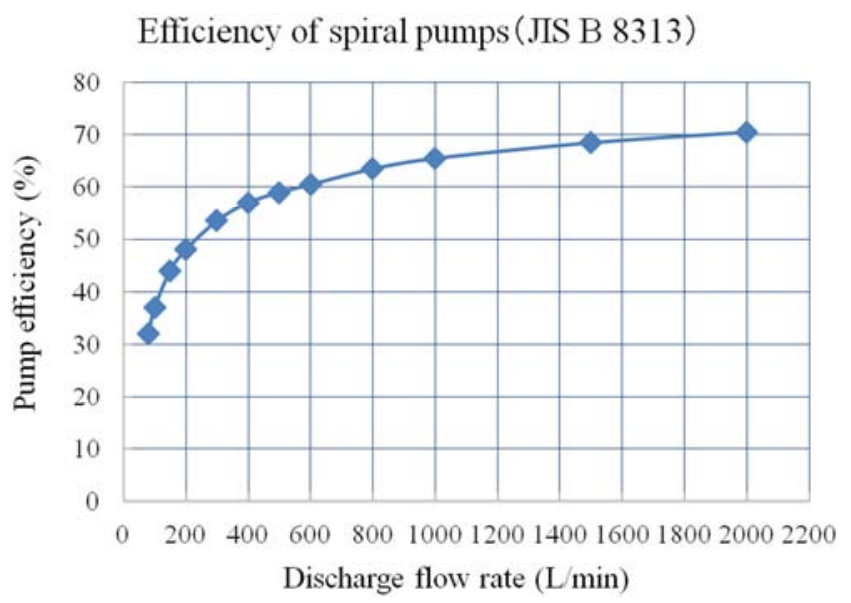

Figure 15. Pump efficiency of centrifugal pump (excerpted from JIS B 8313).

\subsubsection{Evaluation of Energy Loss in Pipeline}

The effective power $P_{\text {water }}$ supplied to the water from the pump is distributed to the pressure loss which is energy consumed per unit time inside the pipeline and the kinetic energy $P_{F}$ of the primary jet ejected from the primary nozzle per unit time.

It is extremely important to reduce the pressure loss inside the pipe in order to increase the ratio of the primary jet energy, which is an effectively available energy.

Supposing that the power consumption due to the pressure loss in the pipe is $P_{P . L \text {, }}$,

$$
P_{P . L .}=P_{\text {water }}-P_{F}
$$

\subsubsection{Breakdown of Energy Consumption in Each Component}

In this section, based on the previous discussion, the energy consumed by each component of the jet pump system is estimated. Figure16 (a) to (d) show the energy consumption distribution of the components of each jet pump model in the case where the inverter output frequency used for driving the motor is $60 \mathrm{~Hz}$ in either case. Further, in all cases, the flow rate distribution ratio of the multi-nozzle model is $q_{1}: q_{2}=60$ : 40.

The total energy $P_{I}$ supplied to the system is divided into motor loss, pump loss, and effective power $P_{\text {water }}$ supplied to 
water. As can be seen from equation (13), the effective power $P_{\text {water }}$ given to water is divided into the power $P_{P . L \text {. }}$ consumed by the pressure loss in the pipe and the power $P_{F}$ possessed by the primary jet.

It can be seen that the multi-nozzle method with a long overall pipe extension has a larger energy loss ratio due to the pressure loss [17] than the single-nozzle method.

\section{Breakdown of energy consumption of single-nozzle injection $[60 \mathrm{~Hz}]$}

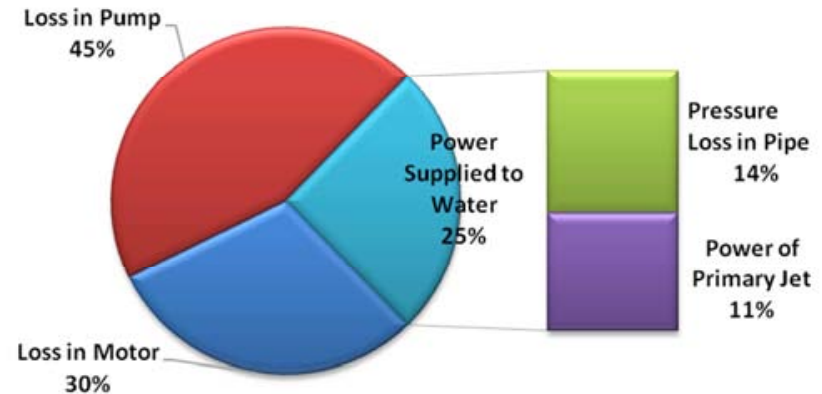

$\square$ Loss in Motor $\square$ Loss in Pump $₫$ Pressure Loss in Pipe $\square$ Power of Primary Jet

(a)

\section{Breakdown of energy consumption of $5^{\circ}$ Multi-nozzle injection $[60 \mathrm{~Hz}]$}

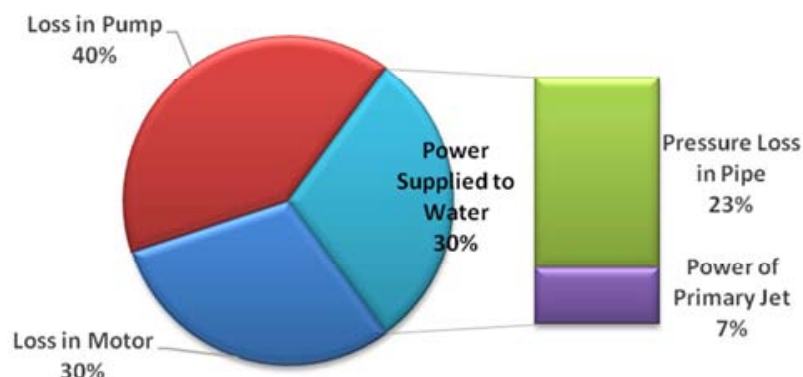

G Loss in Motor $\mathbf{0}$ Loss in Pump $\square$ Pressure Loss in Pipe

(b)

\section{Breakdown of energy consumption of $15^{\circ}$ Multi-nozzle injection $[60 \mathrm{~Hz}]$}

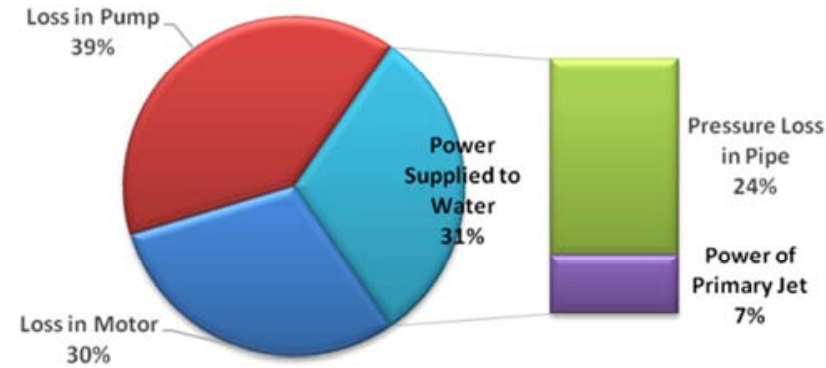

日 Loss in Motor $\mathbf{\theta}$ Loss in Pump $\mathbf{\square}$ Pressure Loss in Pipe Power of Primary Jet

(c)

\section{Breakdown of energy consumption of $30^{\circ}$ Multi-nozzle injection $[60 \mathrm{~Hz}]$}

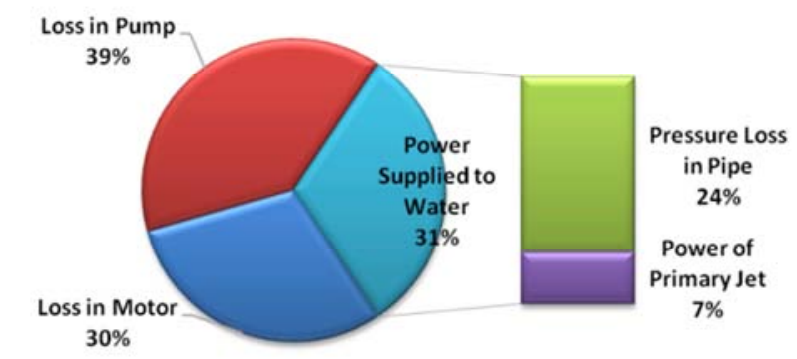

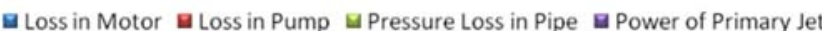

(d)

Figure 16. Breakdown of energy consumption in each model.

\subsubsection{Comprehensive Evaluation of Energy Flow}

In previous sections, the detailed energy flow of the underwater jet pump system has been quantitatively evaluated. Based on the power $P_{I}$ supplied to the system, the system efficiency $\zeta_{\text {sys }}$ for evaluating the output power $P_{S}$ of the secondary jet, which is the final utilization energy of the jet pump, was defined.

On the other hand, the jet pump efficiency $\zeta_{j e t}$, which is an index representing the energy efficiency of the jet pump body itself, is expressed by the ratio between the output $P_{S}$ of the secondary jet and the output $P_{F}$ of the primary jet.

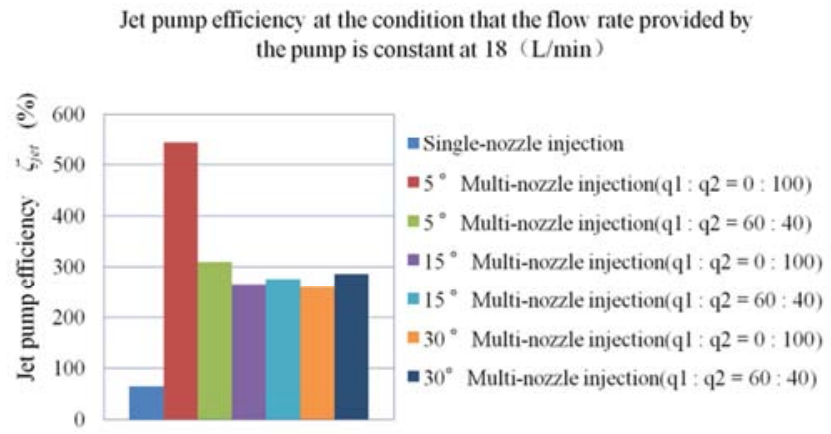

Figure 17. Jet pump efficiency of each injection method.

System efficiency at the condition that the flow rate provided by the pump is constant at $18(\mathrm{~L} / \mathrm{min})$

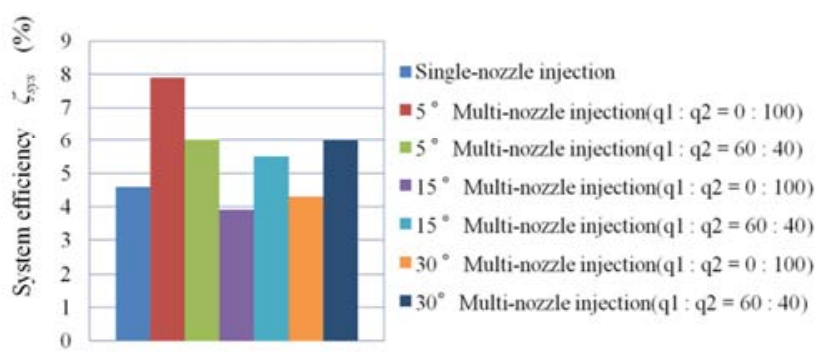

Figure 18. System efficiency of each injection method.

Figure 17 shows data on jet pump efficiency obtained under each experimental condition. From the figure, the conventional single-nozzle system shows a jet pump efficiency of about $60 \%$, whereas the multi-nozzle system 
shows very high efficiency of over $250 \%$ under all experimental conditions. Above all, it is noteworthy that the method using only the side nozzles with an injection angle of $5^{\circ}$ shows very high efficiency exceeding $500 \%$.

On the other hand, Figure 18 shows the system efficiency. From the figure, it is understood that the maximum efficiency is about $8 \%$. As described above, this cause is largely attributable to various losses in the motor and the pump, and the pressure loss inside the pipeline. In the first place, the rated output of the motor and pump used in this experiment is 400 $\mathrm{W}$, and the output is very small as compared with practical machines of several kilowatts to tens of kilowatts. Therefore, as a matter of course, the efficiency of the motor and the pump is low and the pipe diameter is small, so that a large pressure loss occurs. In general, it can be said that it was a system configuration with a large energy loss ratio.

In system design at the time of practical use, it is extremely important in system efficiency improvement to reduce the pressure loss by optimizing the diameter and length of the pipeline when selecting the output of the motor or the pump.

\section{Conclusions and Perspectives}

In this study, in order to greatly improve the efficiency of the underwater jet pump, the performance of the newly invented multi-injection type jet pump and the conventional single-nozzle type jet pump were compared and examined. The followings are the conclusions obtained in this study.

(1) If the primary jet flow rate is constant, the multi-nozzle method can generate more amplified flow rate than the conventional method. In particular, the multi-nozzle system using only the side injection nozzles achieved the maximum amplification efficiency.

(2) When the installation angle of the side injection nozzle is $5^{\circ}$, the best performance was shown in both the amplified flow rate and the amplification factor. As a reason for this, it can be inferred that supplying strong kinetic energy to the boundary layer region inside the secondary nozzle greatly contributes to the performance improvement of the jet pump.

(3) The system efficiency of the jet pump showed the best performance with the method of supplying the primary jet using only the side nozzles in the multi-nozzle model with the installation angle of $5^{\circ}$.

(4) The jet pump efficiency as an index representing the performance of the jet pump body itself was about $60 \%$ in the conventional method, whereas the multi-nozzle injection method showed excellent performance of $250 \%$ or more under all operating conditions. Particularly, in the method of supplying the primary jet using only the side nozzles in the multi-nozzle system with the installation angle of $5^{\circ}$, it exhibited a remarkable performance exceeding 500\%.

Through this research, a future direction toward improving the performance of underwater jet pump was found. In particular, it was confirmed that the multi-injection system newly devised in this research demonstrated higher performance than expected.

Furthermore, it was also revealed that "the injection of jet energy into the boundary layer region inside the secondary nozzle" is a key technology that strongly dominates the performance improvement of underwater jet pump.

The methods for applying the results obtained in this research to actual jet pumps and realizing higher system efficiency and jet pump efficiency are summarized in the following two points.

(i) In order to achieve an increase in system efficiency, design to minimize the pressure loss occurring in the pipeline from the supply pump to the primary nozzle outlet must be carried out. This includes increasing the pipe diameter, shortening the pipeline length, reducing the bending portion of the pipeline [18], optimizing the diameter of the primary nozzle, and so on.

(ii) In order to realize a further increase in jet pump efficiency, it is necessary to inject jet energy effectively by multi-injection into the boundary layer region formed inside the secondary nozzle. By optimizing the injection position, injection angle, number of injection nozzles, etc, further increase in jet pump efficiency is expected.

\section{References}

[1] H. Narui, and S. Inagaki, "Efficiency analysis of jet pumps without diffusers," Transactions of the JSME, Vol. 57, No. 534 (1991), pp. 179-184 (in Japanese).

[2] A. H. Hammoud, "Effect of design and operational parameters on jet pump performance," Proceedings of the 4th WSEAS International Conference on Fluid Mechanics and Aerodynamics, Elounda, Greece, August 21-23, (2006), pp. 245-252.

[3] I. E. L. Neto, "Maximum suction lift of water jet pumps," Journal of Mechanical Science and Technology, Vol. 25, No.2 (2011), pp. 391-394.

[4] S. R. Pandhare, and A. K. Pitale, "Study the performance of water jet pump by changing the angle of mixing nozzle," IJSRST, Vol. 3, No. 3 (2017), pp.538-540.

[5] A. H. Hammoud, and A. A. Abdel Naby, "Slurry Jet Pump Performance Under Different Design and Operational parameters," Proceedings of the 4th WSEAS International Conference on Fluid Mechanics and Aerodynamics, Elounda, Greece, August 21-23, (2006), pp. 237-244.

[6] C. H. Zou, H. Li, P. Tang, and D. H. Xu, "Effect of structural forms on the performance of a jet pump for a deep well jet pump," WIT Transactions on Modeling and Simulation, Vol. 59, Computational Methods and Experimental Measurements XVII (2015), pp.257-266.

[7] S. Mohammad azeez, and A. Venkateswarulu, "Design and analysis of ejector refrigeration system using R-134a refrigerant," International Research Journal of Engineering and Technology, Vol. 5, Issue 6 (2018), pp. 2160-2166.

[8] K. Skrzypek, and R. Grzywacz, "The mixing hydrodynamics and efficiency of the Venturi jet mixer," Technical Transactions 11/2017, Chemistry, pp. 95-106. 
[9] T. Kurokawa, and T. Kodani, "A study on relation between device shape and flow characteristic of jet pump type flow device," Journal of JSCE B1, Vol.71, No.4 (2015), pp. 799 804 (in Japanese).

[10] M. Suzuki, K. Tanaka, and S. Sakuragi, "The operating characteristics of an underwater jet pump," Proceedings of the 3rd IPEJ Chubu District Conference on Research achievements, (2016), pp. 1-4 (in Japanese).

[11] S. Zhao and S. Sakuragi, "Performance improvement of underwater jet pump by optimal arrangement of primary jet stream," Journal of Fluid Science and Technology, Vol.13, No.1, (2018), JFST0004.

[12] R. H. Sabersky, A. J. Acosta, and E. G. Hauptmann, Fluid flow (1971), pp. 64-67, Macmillan.

[13] R. L. Daugherty, J. B. Franzini and E. J. Finnemore, Fluid Mechanics with Engineering Applications, eighth edition (1985), pp. 87-88, McGraw-Hill.
[14] Y. Hagita and S. Sakuragi, "Characteristics of power generation in loop wing wind turbine generator," Proceedings of the 4th IPEJ Chubu District Conference on Research achievements, (2017), pp. 1-4 (in Japanese).

[15] Japanese Industrial Standards JIS C 4210; Low-voltage three-phase squirrel cage induction motor for general use (in Japanese).

[16] Japanese Industrial Standards JIS B 8313; Small spiral pump (in Japanese).

[17] Y. Lahiouel and R. Lahiouel, "Evaluation of Energy Losses in Pipes," American Journal of Mechanical Engineering, Vol. 3, No. 3A, 2015, pp. 32-37.

[18] K. H. Beij, "Pressure losses for fluid flow in $90^{\circ}$ pipe bends," Journal of Research of the National Bureau of Standards, Volume 21, July 1938, Research Paper RP1110. 